\title{
Endoscopic closure of a 6-cm long esophageal defect with tracheoesophageal fistula
}

A 68-year-old man with metastatic esophageal adenocarcinoma previously treated with esophagectomy and chemoradiation presented with new-onset dysphagia and cough. A recent good response to chemotherapy resulted in shrinkage of a 7-cm mediastinal metastasis. Chest computed tomography revealed a large esophageal defect. A barium swallow confirmed the presence of a tracheoesophageal fistula (TEF). Upper endoscopy showed a 6 -cm defect on the anterior esophageal wall with a clear opening into the trachea ( - Video 1).

An upper gastroscope was advanced to the esophagojejunostomy. A 0.035 -inch guidewire was passed through the scope and coiled within the jejunum. The scope was withdrawn while maintaining the position of the wire and a double-channel endoscope was fitted with an endoscopic suturing device. The defect was closed using two running sutures, with an average of 5 bites per suture. Immediately after suturing, the patient's capnography improved significantly. Subsequently, a $23 \mathrm{~mm} \times 12 \mathrm{~cm}$ fully covered self-expandable metal stent was successfully placed, with the proximal flange positioned at $2 \mathrm{~cm}$ above the esophageal defect and just distal to the upper esophageal sphincter ( $\triangleright$ Fig.2). The esophageal stent was secured with two sutures (\Fig.3). A subsequent esophagram showed no extravasation of contrast ( $>$ Fig.4). The patient tolerated an oral diet and was discharged home in a good condition.

TEF is a rare yet life-threatening condition that develops in up to $5 \%$ of patients with esophageal malignancy [1]. Management is challenging, and closure often requires a multidisciplinary approach and is associated with high rates of recurrence [2]. Surgery is associated with extremely high morbidity, and endoscopic therapy has been proposed as a

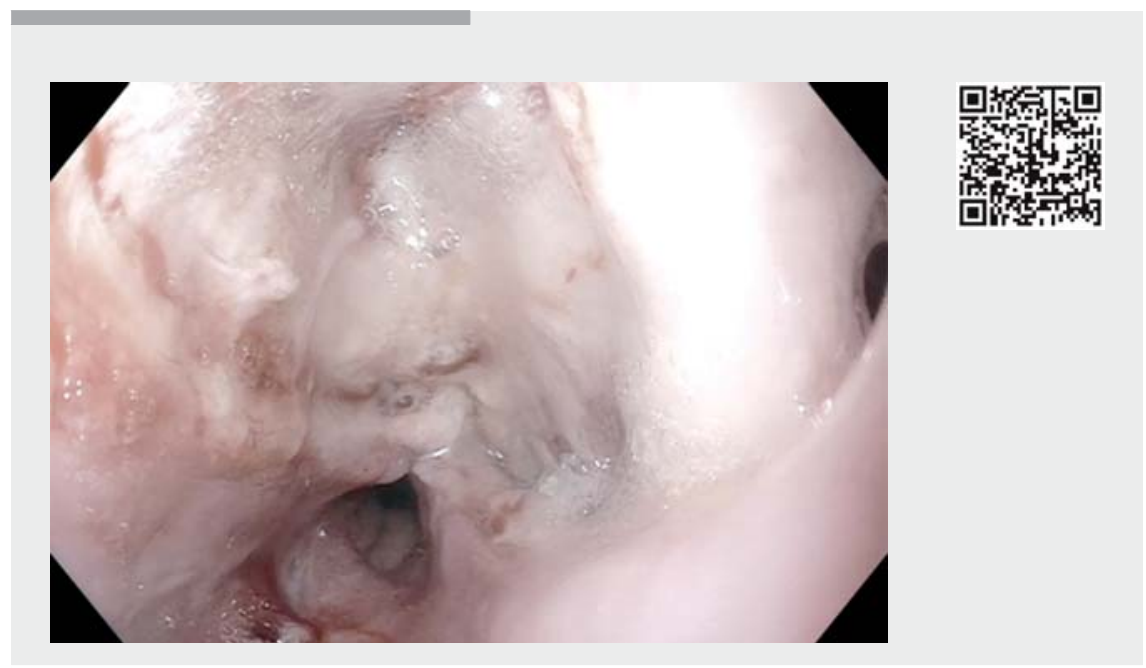

$\checkmark$ Video 1 Successful closure of a large tracheoesophageal fistula using combined modalities of endoscopic suturing and metal stent placement.

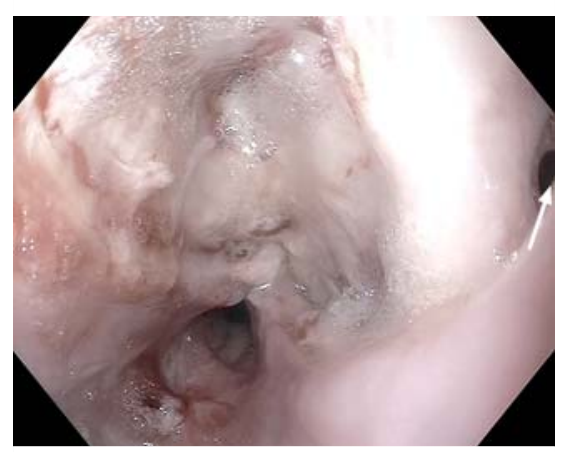

- Fig. 1 Endoscopic view of a large esophageal defect and tracheoesophageal fistula (arrow) in the upper esophagus.

minimally invasive and relatively safe modality that improves the quality of life in patients with TEF $[3,4]$. The current case demonstrates that very large esophageal defects and fistulae can be successfully closed using a multi-modality approach of endoscopic suturing and stent placement.

Endoscopy_UCTN_Code_TTT_1AO_2AI

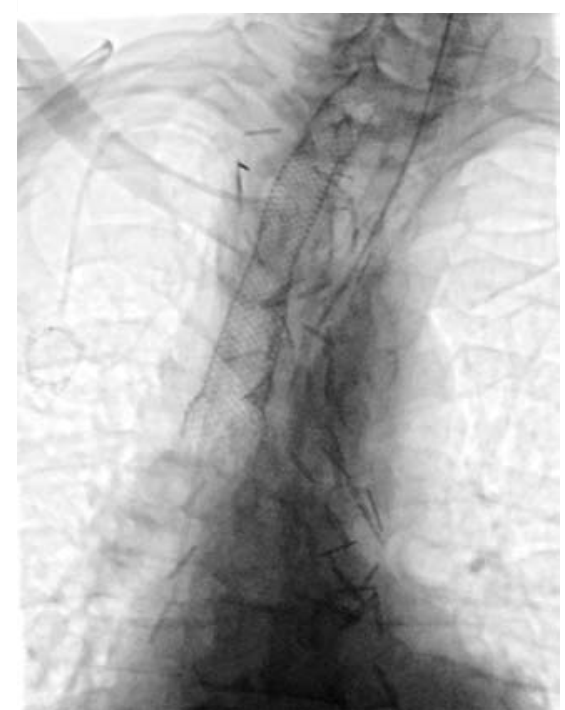

- Fig. 2 A fully covered self-expandable metal stent was successfully deployed traversing the defect. 


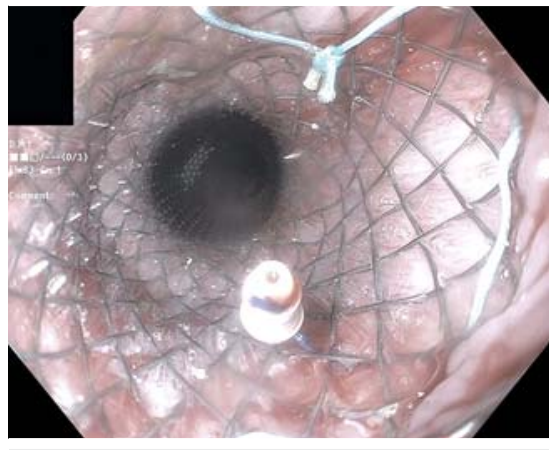

Fig. 3 The proximal flange of the stent was sutured to the esophageal wall to prevent stent migration.

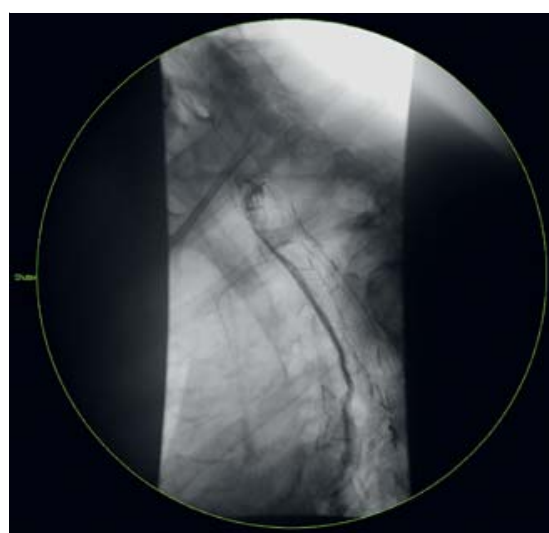

- Fig. 4 Barium swallow test showing no extravasation of contrast confirming complete closure.

\section{Competing interests}

Dr. Sharaiha is a consultant for Boston Scientific, Olympus, Apollo, and Medtronic. Dr. Carr-Locke is a consultant for Steris, Telemed, Boston Scientific, Valentx, Ergogrip, and Screwire.
The authors

Danny Issa, Qais Dawod, Marwan Azzam, Kartik Sampath, David Carr-Locke, Reem Z. Sharaiha

Division of Gastroenterology and Hepatology, New York Presbyterian Hospital/Weill Cornell Medical Center, New York, New York, United States

\section{Corresponding author}

\section{Reem Z. Sharaiha, MD}

Division of Gastroenterology and Hepatology Department of Medicine, Weill Cornell Medicine, 1305 York Avenue, 4th Floor, New York, New York 10021, United States

Fax: +1-646-962-0110

rzs9001@med.cornell.edu

\section{References}

[1] Bartels HE, Stein HJ, Siewert JR. Tracheobronchial lesions following oesophagectomy: prevalence, predisposing factors and outcome. Br J Surg 1998; 85: 403-406

[2] Ramai D, Bivona A, Latson W et al. Endoscopic management of tracheoesophageal fistulas. Ann Gastroenterol 2019; 32: 24-29

[3] Kovesi T, Rubin S. Long-term complications of congenital esophageal atresia and/or tracheoesophageal fistula. Chest 2004; 126 : 915-925

[4] Balazs A, Kupcsulik PK, Galambos Z. Esophagorespiratory fistulas of tumorous origin. Non-operative management of 264 cases in a 20-year period. Eur J Cardiothorac Surg 2008; 34: $1103-1107$

\section{Bibliography}

DOI https://doi.org/10.1055/a-0885-9494

Published online: 23.5.2019

Endoscopy 2019; 51: E286-E287

(c) Georg Thieme Verlag KG

Stuttgart · New York

ISSN 0013-726X

\section{ENDOSCOPY E-VIDEOS}

https://eref.thieme.de/e-videos

Endoscopy E-Videos is a free access online section, reporting 自社: on interesting cases and new

techniques in gastroenterological endoscopy. All papers include a high quality video and all contributions are freely accessible online.

This section has its own submission website at https://mc.manuscriptcentral.com/e-videos 